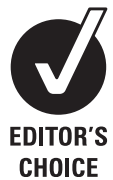

CHOICE
${ }^{1}$ Department of Hospital Medicine, Cleveland Clinic, Cleveland, Ohio, USA

${ }^{2}$ Center for Pediatric Hospital Medicine, Children's Hospital, Cleveland Clinic, Cleveland, Ohio, USA

\section{Correspondence to}

Moises Auron, Department of Hospital Medicine, Cleveland Clinic, 9500 Euclid Ave, M2 Annex, Cleveland, $\mathrm{OH} 44195$, USA; auronm@ccf.org

Received 28 October 2010 Accepted 21 February 2011 Published Online First 25 March 2011

\title{
Renin-angiotensin system antagonists in the perioperative setting: clinical consequences and recommendations for practice
}

\author{
Moises Auron, ${ }^{1,2}$ Brian Harte, ${ }^{1}$ Ajay Kumar, ${ }^{1}$ Franklin Michota ${ }^{1}$
}

\begin{abstract}
There are no existing guidelines supporting the withdrawal or continuation of renin-angiotensin-aldosterone system (RAAS) antagonists in the preoperative setting. RAAS antagonists include ACE inhibitors, angiotensin II receptor subtype 1 blockers and direct renin inhibitors (eg, aliskiren), as well as the aldosterone antagonists. The use of these agents before surgery has been associated with a variable incidence of hypotension during the initial 30 min after induction of anaesthesia; however, these hypotensive episodes have not been conclusively linked to any significant postoperative complications, although recent data suggest an increase in postoperative morbidity and mortality in patients undergoing coronary artery bypass grafting. Further studies are required to be able to demonstrate if the organ-protective benefits of RAAS antagonists justify their continuation in the perioperative setting. Temporary withdrawal of RAAS antagonists in these patients may prevent or attenuate intraoperative hypotension and hypovolaemia.

Alternatively, the increase in RAAS activity and blood pressure expected with cessation of RAAS antagonist therapy may impair regional circulation secondary to an increase in systemic vascular resistance. Full discussion of the potential implications of perioperative RAAS antagonist therapy with the surgical team is important, and strategies to ensure careful monitoring and maintenance of adequate intravenous volume before induction of anaesthesia are essential.
\end{abstract}

\section{INTRODUCTION}

The renin-angiotensin-aldosterone system (RAAS) antagonists include ACE inhibitors (ACEIs), angiotensin II receptor subtype 1 blockers (ARBs) and direct renin inhibitors (eg, aliskiren). The use of these agents has increased substantially in the past two decades, and they currently are among the most commonly used and effective treatments for hypertension, ${ }^{1}$ congestive heart failure, ${ }^{2}$ coronary artery disease ${ }^{3}$ and diabetic nephropathy. ${ }^{4}$ As a result, many contemporary surgical patients will be using RAAS antagonists before their procedure, and questions remain as to the potential risks and/ or benefits of continuing these agents in the immediate perioperative period.

There have been several reports and small studies suggesting that intraoperative hypotension after the induction of anaesthesia is more common in patients who receive RAAS antagonist therapy on the day of surgery. ${ }^{6}$ Similar reports have linked postoperative acute renal failure with RAAS antagonist use before surgery, which is related to both intraoperative hypotension and use of inotropes. ${ }^{78}$ Although most of the existing literature has not associated the perioperative use of these agents with an increase in short- or long-term mortality, one recent analysis has found a higher incidence of postoperative atrial fibrillation (POAF), use of inotropes, and death with preoperative RAAS antagonist therapy. ${ }^{8}$

The available literature on this topic is scant, and no guidelines have yet been published on the appropriate use of RAAS antagonists in the surgical patient. In addition, the introduction of new agents that modulate RAAS, such as the direct renin inhibitor aliskiren, will add further complexity to this important clinical question. The purpose of this review is to compare and contrast the existing literature supporting the use or cessation of RAAS antagonists in both cardiac and non-cardiac surgery patients, and to provide further insight for the clinician caring for such patients in the perioperative period.

\section{PHARMACOLOGICAL PROPERTIES AND PERIOPERATIVE IMPLICATIONS}

The vasodilatory actions of RAAS antagonists involve multiple mechanisms (tables 1 and 2). These include direct sympathetic blockade, increased bioavailability of vasodilators such as bradykinin, nitric oxide and prostacyclins, inhibition of the direct and indirect vasoconstrictor effects of angiotensin II, and reduced secretion of aldosterone and antidiuretic hormone resulting in a decrease in salt and water reabsorption by the kidney. ${ }^{11}$ Given the wide distribution of ACE in the body, the RAAS antagonists have wide-ranging effects, inhibiting various angiotensin peptides as well as both renin and pro-renin receptors with subsequent endocrine, paracrine and intracrine functions, which in turn regulate diverse physiological functions (figure 1). ${ }^{12}{ }^{13}$ There are welldefined deleterious effects of chronic RAAS stimulation such as upregulation of angiotensin 1 receptor, subsequent aldosterone release, and the promotion of vascular hypertrophy, fibrosis and proliferation. There are also novel components of the RAAS that exert unclear effects, such as a homologue of ACE called ACE 2, which mediates the formation of the heptapeptide $\mathrm{Ang}^{1-7}$, a peptide with both vasodilatory and vascular endothelial anti-inflammatory properties. ${ }^{14} 15$ The RAAS, along with sympathetic nervous system activation and arginine-vasopressin (AVP) release, is a primary mechanism for the maintenance of 
Table 1 Pharmacology of ACE inhibitors

\begin{tabular}{llllll}
\hline & $\begin{array}{l}\text { Active } \\
\text { metabolite }\end{array}$ & Zinc ligand & Bioavailability (\%) & Half-life (h) & $\begin{array}{l}\text { Route of } \\
\text { elimination }\end{array}$ \\
\hline Captopril & No & Sulfhydryl & $75-91$ & 1.7 & Kidney \\
Enalapril & Yes & Carboxyl & 60 & 11 & Kidney \\
Lisinopril & No & Carboxyl & $6-60$ & 12 & Kidney \\
Benazepril & Yes & Carboxyl & $>37$ & $10-11$ & Kidney \\
Quinapril & Yes & Carboxyl & $>60$ & $1.9-2.5(25$ terminal) & Kidney \\
Ramipril & Yes & Carboxyl & $50-60$ & Triphasic $4,9-18,>50$ & Kidney \\
Trandolapril & Yes & Carboxyl & 70 & $15-24$ & Kidney, liver \\
Moexipirl & Yes & Carboxyl & 13 & $2-9$ & Kidney \\
Fosinopril & Yes & Phosphinyl & 36 & 12 & Liver, kidney \\
\hline
\end{tabular}

Adapted from Brown and Vaughan. ${ }^{9}$

venous return and systemic blood pressure (SBP) during periods of acute haemodynamic stress such as the induction of anaesthesia. Angiotensin II is a potent direct vasoconstrictor and physiological stimulus for AVP release, and counter-regulates the usual hypotensive effect of anaesthetic agents on the sympathetic nervous system (increased venous pooling of blood, decreased cardiac output, and arterial hypotension). As a result, patients chronically treated with RAAS antagonists are potentially at higher risk of developing clinically significant hypotension after the induction of anaesthesia because of the decreased vascular resistance and associated decreased cardiac filling. ${ }^{6} 1617$ The withdrawal of these agents should reduce the hypotensive episodes, but may also increase systemic vascular resistance, which can compromise regional circulation (splanchnic).

Because the RAAS interacts at multiple levels to maintain intraoperative blood pressure (BP), the successful treatment of intraoperative hypotension in the setting of RAAS blockade includes adequate intravascular volume repletion, as well as the use of AVP agonists (terlipressin, vasopressin) and adrenergic agonists. In the USA, vasopressin is the only available AVP agonist. ${ }^{18}$ AVP agonists potentiate the response to endogenous catecholamines, which increases vascular resistance and venous return and improves myocardial oxygen delivery and cardiac contractility. ${ }^{19}$

Complicating matters further, recent pharmacogenomic studies of the RAAS have demonstrated variable genetic susceptibility to RAAS antagonists via single-nucleotide polymorphisms in the genes that encode angiotensinogen, angiotensin receptor 1 and angiotensin receptor $2 .^{20} 21$ The most comprehensively studied RAAS polymorphism is the ACE insertion/deletion polymorphism; this is based on the presence (I) or absence (D) of a 287 bp Alu repeat sequence within intron 16 of the ACE gene. The D allele has been associated with increased ACE concentrations in plasma and at the tissue level, and its expression (DD allele) has been postulated to offer

Table 2 Pharmacology of angiotensin receptor II type 1 blockers

\begin{tabular}{llllll}
\hline & $\begin{array}{l}\text { Active } \\
\text { metabolite }\end{array}$ & $\begin{array}{l}\text { Bioavailability } \\
\text { (\%) }\end{array}$ & $\begin{array}{l}\text { Half-life } \\
\text { (h) }\end{array}$ & \multicolumn{2}{l}{$\begin{array}{l}\text { Route of } \\
\text { elimination (\%) }\end{array}$} \\
\hline Kidney & Liver \\
\hline Losartan & Yes & 33 & 2 & 40 & 60 \\
Valsartan & No & 25 & 9 & 15 & 85 \\
Irbesartan & No & 70 & $11-15$ & 20 & 80 \\
Candesartan & Yes & 42 & $3.5-4$ & 35 & 65 \\
Telmisartan & No & 43 & 24 & 1 & 99 \\
Eprosartan & No & 15 & $5-7$ & 10 & 90 \\
Olmesartan & Yes & 26 & 13 & $35-50$ & $50-65$ \\
\hline
\end{tabular}

Adapted from Barreras and Gurk-Turner. ${ }^{10}$ resistance to ACE inhibitors and cause increased adverse cardiovascular and renal effects. ${ }^{22} 23$ Thus the haemodynamic response to RAAS antagonists in the perioperative setting may be further influenced by individual genetics.

\section{EVIDENCE AGAINST RAAS ANTAGONISTS IN THE PERIOPERATIVE SETTING}

The current medication guideline used at the perioperative clinic in our institution recommends that both ACEIs and ARBs be discontinued on the morning of non-cardiac surgery. ${ }^{24}$ There are no national or international guidelines that delineate a standard of care in the use of these agents in the perioperative period. The literature supporting this practice relates to the frequency and degree of intraoperative hypotension observed with concomitant use of RAAS antagonists.

\section{Non-cardiac surgery}

The following studies focused on the effect on BP after intubation in patients taking ACEIs before surgery.

McCarthy et al studied the effect of two doses of sublingual captopril (12.5 mg and $25 \mathrm{mg}$ ) versus placebo administered $25 \mathrm{~min}$ before tracheal intubation in 40 patients. The patients receiving captopril were more likely to develop hypotension than those receiving placebo $(p<0.05)$ within 3 min of intubation; however, there was no significant difference between the two captopril doses. ${ }^{25}$ Coriat et al randomised 56 patients undergoing non-cardiac surgery chronically treated for hypertension with captopril $(n=36)$ or enalapril $(n=20)$ into two groups, one in which the ACEIs were administered on the morning of surgery and the other in which it was withdrawn. In the former group, all of the patients who received enalapril and $64 \%$ of those who received captopril required ephedrine to treat post-induction hypotension. The rate was significantly higher than in the patients whose ACEIs were withdrawn (enalapril $100 \%$ vs $18 \%, p<0.005$; captopril $64 \%$ vs $21 \%, p<0.05) .{ }^{26}$

The difference in haemodynamic response between ACEIs and ARBs was demonstrated in a study by Brabant et al. Haemodynamic responses were evaluated in patients treated with $\beta$-adrenergic blockers (BBs) and/or calcium channel blockers (CBs), ACEIs or ARBs after induction of anaesthesia. Hypotension was defined as an SBP decrease of $>30 \%$ from the preoperative value or an absolute SBP decrease below $90 \mathrm{~mm} \mathrm{Hg}$. Hypotension occurred in $100 \%$ of patients receiving ARBs (12 out of 12 ), compared with $60 \%$ of BB/CB-treated patients (27 of 45 ) or with $66 \%$ of ACEI-treated patients (18 of 27$)(p \leq 0.05)$. After induction of anaesthesia, the lowest mean arterial pressure ( $\mathrm{mm} \mathrm{Hg}$ ) was $54 \pm 6$ in the ARB group, $66 \pm 12$ in the $\mathrm{BB} / \mathrm{CB}$ group, and $68 \pm 10$ in the ACEI group ( $p<0.001$ comparing $A R B$ with $\mathrm{CC} / \mathrm{BB}$ or $\mathrm{ACEI}$ groups). The patients treated with $\mathrm{ARBs}$ 


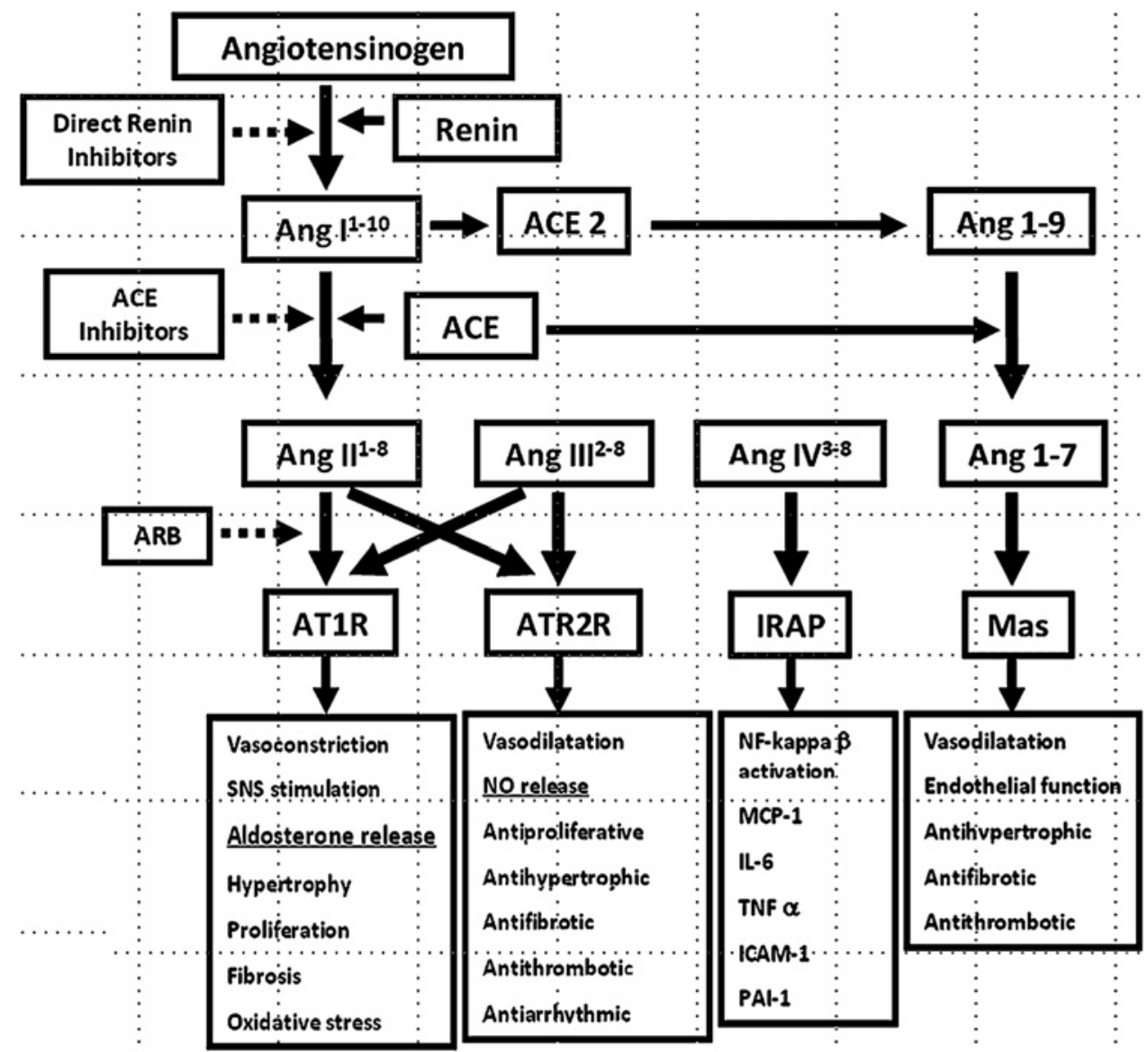

Figure 1 Renin-angiotensin-aldosterone system (RAAS) and site of action of the different RAAS antagonists. Note the pleiotropic effects of the RAAS that can be indirectly affected by the use of RAAS antagonists given its activity. Ang III-angiotensin 2-8 heptapeptide has similar activity to Ang $\mathrm{II}$, as well as acts on angiotensin type 2 receptors. Ang IV-angiotensin 3-8 hexapeptide exerts its actions via insulin-regulated amino peptidase receptors (IRAP) with subsequent expression of inflammatory and immune mediators. Ang 1-9 (angiotensin 1-9 nanopeptide) is a precursor of Ang 1-7 via ACE 2 (homologue of ACE). Ang 1-7 (angiotensin 1-7 heptapeptide) acts via Mas receptors. Adapted from: Fyhrquist F, Saijonmaa 0.

Renin-angiotensin system revisited. J Intern Med 2008;264:224-36. Varagic J, Trask AJ, Jessup JA, et al. New angiotensins. J Mol Med 2008;86:663-71. Ferrario CM. New physiological concepts of the renin-angiotensin system from the investigation of precursors and products of angiotensin I metabolism. Hypertension 2010;55:445-52. ARB, angiotensin receptor II type 1 blocker; ICAM, intracellular adhesion molecule; IL, interleukin; MCP, monocyte chemoattractant protein; PAl, platelet activation inhibitor-1; SNS, sympathetic nervous system; TNF, tumour necrosis factor.

required higher doses of adrenergic agents (ephedrine, phenylephrine) (4 of 12) compared with the BB/CB group ( 0 of 45 ) or the ACEI group (1 of 27); however, the hypotension was responsive to vasopressin agonists. ${ }^{27}$

Several studies have focused on the time that RAAS antagonists should be withheld before surgery. Bertrand et al studied 37 patients receiving chronic therapy with ARBs; 18 had their ARBs discontinued the day before surgery, and 19 received their ARB dose $1 \mathrm{~h}$ before induction of anaesthesia. He found that the administration of ARBs on the morning of surgery was associated with more frequent episodes of hypotension as well as longer duration of hypotension than if ARBs was withheld. In addition, the hypotensive episodes were refractory to initial therapy with adrenergic agents, requiring the addition of terlipressin. This study also found that the timing of the RAAS antagonist did play a role in the outcome. Patients that received an ARB dose within $10 \mathrm{~h}$ of anaesthesia induction were more likely to have hypotension than patients receiving the ARB dose more than $10 \mathrm{~h}$ before the induction of anaesthesia. The authors recommended discontinuing ARBs on the day before surgery. ${ }^{28}$

Comfere et al evaluated 267 patients receiving chronic antihypertensive treatment with ACEIs/ARBs undergoing general anaesthesia. The incidence of hypotension during the first
30 min after induction of anaesthesia was more common in patients whose most recent ACEIs/ARBs was taken $<10 \mathrm{~h}$ compared with those who stopped it $>10 \mathrm{~h}$ before induction ( $60 \%$ vs $46 \%$, OR 1.74 (95\% CI 1.03 to 2.93 ), $p=0.04$ ). ${ }^{29}$

Shirmer and Schurmann randomised 100 patients receiving chronic antihypertensive therapy with ACEIs in a double-blind study of ACEI discontinuation in non-cardiac surgery. Fifty patients were allocated to receive ACEIs on the morning of surgery and 50 to have it withdrawn. After induction of anaesthesia, the $\mathrm{BP}$ and heart rate were significantly lower in the group of patients receiving ACEIs than in the withdrawal group, and the use of supportive adrenergic agonists was required more often (17 of the 50 patients who took ACEIs versus five of the 50 patients in the withdrawal group, $p<0.05$ ). The authors concluded that patients chronically treated with ACEIs should receive the last dose on the day before surgery. ${ }^{30}$

The effect of sympathetic blockade of RAAS antagonists in the perioperative setting was evaluated by Licker et al, who compared in a prospective case-control study, the heart rate variability and baroreflex control before surgery and $30 \mathrm{~min}$ after induction of anaesthesia in two groups of patients with ischaemic heart disease undergoing non-cardiac surgery (16 receiving chronic ACEIs and 16 who did not) and found no 
significant effect of ACEIs on cardiac autonomic regulation as measured by baroreflex sensitivity. All patients had normal cardiac function. Anaesthesia-related hypotension was defined by SBP $<90 \mathrm{~mm} \mathrm{Hg}$. Baroreflex sensitivity was estimated after $\mathrm{BP}$ changes induced by injections of phenylephrine and nitroglycerin. Anaesthesia-related hypotension occurred in nine patients in the ACEI group versus only two controls, and they found a diminished response to phenylephrine in the ACEI group. The authors determined that anaesthetic-induced hypotension is mainly an effect of decreased adrenergic vasoconstrictive response. ${ }^{31}$

A systematic review with random-effects meta-analysis (five studies; $\mathrm{N}=434$ patients) found a greater likelihood of hypotension requiring vasopressors at or shortly after induction of anaesthesia in the setting of preoperative RAAS antagonist administration on the day of surgery (RR 1.50, 95\% CI 1.15 to 1.96). Despite this, the incidence of perioperative myocardial infarction was not significantly different between groups continuing or stopping RAAS antagonists (RR 0.41, 95\% CI 0.07 to 2.53). It should be noted that this analysis was not controlled for cardiac risk factors, as data were insufficient for subgroup comparisons. ${ }^{32}$ In a subsequent large prospective observational study of 12381 patients undergoing non-cardiac surgery, with similar cardiovascular and pulmonary comorbidities controlled by propensity score matching, the concomitant use of diuretics along with RAAS antagonists increased both intraoperative hypotension and requirement for vasopressors compared with ACEIs alone or when used in combination with calcium-channel blockers. It should be noted that all hypertensive patients were excluded from the study. There were no statistically significant differences in postoperative renal failure or myocardial ischaemia between patients receiving RAAS alone versus RAAS and diuretics. $^{33}$

A recent study addressing the effect of RAAS blockade on 30-day mortality was conducted by Railton et al. They demonstrated an increase in postoperative 30-day mortality in patients using RAAS inhibitors before surgery in an observational cohort study of 883 consecutive patients undergoing elective open abdominal aortic aneurysm repair. RAAS blockers were used before surgery by 359 patients compared with 524 who did not. The overall 30 -day mortality was $3.5 \%$ (31/883 patients). Analysis of 261 propensity score-matched pairs showed a 30-day mortality of $6.1 \%(16 / 261)$ in the patients with RAAS blockade compared with $1.5 \%(4 / 261)$ in the unblocked patients (OR 5.0, $95 \%$ CI 1.4 to $27 ; \mathrm{p}=0.008) .{ }^{34}$

\section{Cardiac surgery}

Most of the negative outcomes related to the use of RAAS antagonists before cardiac surgery (regardless of whether the patients undergo cardiopulmonary bypass (CPB)) are believed to be related to the development of intraoperative hypotension requiring vasopressor support ${ }^{35-37}$; however, other potential adverse outcomes include intraoperative reduction in cardiac output, $^{38}$ postoperative decline in renal function, ${ }^{7}$ atrial fibrillation, and even death. ${ }^{8} 39$

Vasoplegic syndrome is a form of vasodilatory shock that can occur after CPB. In a prospective study of 145 patients undergoing $\mathrm{CPB}$, two independent predictors of development of vasodilatory shock after discontinuation of $\mathrm{CPB}$ were identified: ejection fraction (EF) $<35 \%(O R$ 11.9, 95\% CI 2.7 to 53.1; $\mathrm{p}=0.003$ ) and ACEI use (OR 9.1, 95\% CI 2.1 to 38.8; $\mathrm{p}=0.001$ ). These patients responded well to AVP infusions. ${ }^{40}$ In a subsequent retrospective study (2002-2006) of 2823 adult cardiac surgery cases, Levin et al found that 577 (20.4\%) developed post-CPB vasoplegic syndrome; these patients had an increased inpatient mortality and length of stay $>10$ days (OR 3.30; 95\% CI 1.44 to 7.57; $p<0.005$ ). The preoperative use of ACEIs was associated with a modest increase in the risk of vasoplegia (OR 1.37, 95\% CI 1.04 to 1.80; $\mathrm{p}=0.026)^{38}$

In a study of 249 patients who underwent aortic surgery, Cittanova et al found that 61 developed postoperative renal impairment, defined as a $20 \%$ decrease in baseline glomerular filtration rate (GFR), 7 days after surgery. Chronic treatment with ACEIs was the only factor significantly associated with postoperative renal impairment even after exclusion of patients with $\mathrm{EF}<35 \%$ (OR 2.01, 95\% CI 1.05 to 3.83; $\mathrm{p}=0.034)^{7}$

The association of hypotension with intraoperative decrease in cardiac output was described by Colson et al, who studied 16 hypertensive patients (eight receiving ACEIs, and eight receiving a combination of other antihypertensive agents) who underwent coronary artery bypass grafting (CABG) or vascular surgery. In ACEI-treated patients, the hypotension was associated with a consistent decrease in pulmonary capillary wedge pressure $(-26.4 \% ; \quad p=0.035)$ and cardiac index $(-23.9 \% ; p=0.001)$, suggesting that the post-induction hypotension in patients using ACEIs is secondary to poor cardiac output during acute decreases in ventricular volume. Although the sample size was small, this study is important in that it was the first to address the effect of ACEIs on intraoperative cardiac output and to have used the same anaesthetic technique in all patients to avoid confusing variables. ${ }^{35}$

A prospective non-randomised study to address the utilisation of vasopressor therapy in patients taking ACEIs on CPB was carried out by Tuman et al. In 4301 adults undergoing elective coronary artery and/or valve surgery, they identified 519 patients taking ACEIs before surgery, and 3782 that were not. Preoperative ACEI use was identified as an independent risk factor for multiple ( $>2$ ) vasoconstrictor infusions after extracorporeal CPB to keep $\mathrm{SBP}>85 \mathrm{~mm} \mathrm{Hg}(\mathrm{OR}=1.53,95 \%$ CI 1.05 to 2.25; $\mathrm{p}=0.0301){ }^{36}$

Deakin et al studied 62 sequential adult patients undergoing cardiac surgery requiring hypothermic $\left(28^{\circ} \mathrm{C}\right) \mathrm{CPB}$. Twenty-one patients were receiving ACEIs before surgery. Preoperative ACEI therapy was associated with a significant decrease in systemic vascular resistance during the rewarming phase of $\mathrm{CPB}$ $(p=0.006)$ and increases in post-CPB vasoactive drug requirements ( $R R$ 3.32, 95\% CI 1.43 to $7.71 ; p=0.01$ ). This study is unfortunately limited by its small size, non-randomised design, and inability to identify whether the hypotension was linked to low systemic vascular resistance or low cardiac output. ${ }^{37}$

The effects of preoperative ACEI use in patients undergoing CABG without CPB (off pump) were studied by Lee et al. They compared 43 patients treated with ACEIs for at least 4 weeks before surgery with 37 patients who did not receive ACEIs There was greater utilisation of vasoconstrictors in the ACEI group especially during anastomosis of the obtuse marginal branch of the left circumflex artery. The study was limited by its relatively small sample size, non-randomised design, and presence of other multiple confounding factors such as diabetes and hypertension which can affect haemodynamic parameters. ${ }^{41}$

Boeken et al studied 240 patients undergoing cardiac surgery (CABG or valvular) and divided them in a non-randomised fashion into three groups: group A used pre- and post-operative ACEIs; group B used preoperative ACEIs only; group C used no ACEIs. They did find a significant increase in intra- and postoperative catecholamine use in the patients using preoperative ACE $(p<0.05)$. In the ACEI groups, nine patients developed systemic inflammatory response syndrome compared with only two cases in group $\mathrm{C}$, suggesting that the vasodilatory effect of 
RAAS inhibition may predispose to 'post-perfusion syndrome' and systemic inflammatory response syndrome. Interestingly, four patients in group B (no postoperative ACEI use) had postoperative disturbances of the intestinal microcirculation, suggesting that the withdrawal of ACEIs in patients with chronic use may further predispose to microcirculation derangements. ${ }^{42}$

A best evidence topic review addressing whether preoperative cessation of RAAS antagonists in cardiac surgery permits avoidance of postoperative vasodilatation was performed by Raja and Fida. They initially examined 421 articles and ultimately selected three randomised controlled trials and seven large cohort and case-control studies. The authors concluded that preoperative administration of ACEIs and ARBs in patients undergoing cardiac surgery contributes to a postoperative decrease in systemic vascular resistance and vasoplegia, and that withholding ACEIs and ARBs before cardiac surgery is reasonable to avoid postoperative vasodilatation; however, the evidence supporting this decision is weak. ${ }^{43}$

Miceli et al performed a retrospective observational cohort study (1996-2008) of 10023 patients undergoing isolated CABG. Of these, 3052 patients receiving preoperative ACEIs were matched with a control group by propensity score analysis. Patients receiving preoperative ACEIs were more likely to have an $\mathrm{EF}<50 \%$ (32.8\% vs $20.2 \%$ ). They found that preoperative use of ACEIs was an independent predictor of mortality (OR 2.83, 95\% CI 1.03 to $7.8 ; p=0.04$ ), was associated with an increased risk of postoperative renal dysfunction (OR $1.7,95 \%$ CI 1.22 to 2.38; $\mathrm{p}=0.0002$ ), was an independent risk factor for POAF (OR $1.33,95 \%$ CI 1.17 to $1.51 ; p=0.0001$ ), and was associated with increased use of inotropic support (OR 1.17, 95\% CI 1.07 to 1.29; $\mathrm{p}=0.0001$ ). The overall mortality was $1 \%$. Preoperative ACEIs were associated with a doubling of the mortality risk $(1.3 \%$ vs $0.7 \%$; OR $2.00,95 \%$ CI 1.17 to $3.42 ; \mathrm{p}=0.013$ ). The main limitations of this study are its retrospective nature, the inability to distinguish between the use of ACEIs and ARBs, and the lack of information with regard to drug dose and timing. ${ }^{8}$

Magee et al developed a predictive risk algorithm to determine the possibility of developing postoperative atrial fibrillation using a database of 19083 patients who underwent CABG (1995-2006). Among the risk factors, the preoperative use of ACE inhibitors was associated with a modest increase in the development of POAF (OR 1.123, 95\% CI 1.045 to 1.205; $\mathrm{p}<0.001)$. However, it should be mentioned that the algorithm had modest validation scores (receiver operating characteristic curve area of 0.72 and concordance between observed and predicted of $72.3 \%$ ). ${ }^{39}$

In a recent large observational study, Rader et al evaluated the relationship of preoperative use of RAAS inhibition with ACEIs or ARBs within $24 \mathrm{~h}$ of surgery and the development of POAF in patients undergoing CABG. Preoperative RAAS inhibition occurred in 4795 patients versus 5757 who did not. In the patients receiving RAAS inhibition, 1725 (36\%) developed POAF compared with 1908 (33\%) (OR 1.13, 95\% CI 1.05 to 1.25; $\mathrm{p}<0.01)$. However, after propensity score matching, there was no significant association between preoperative RAAS inhibition and POAF (OR 1.05, 95\% CI 0.95 to 1.16; $\mathrm{p}=0.38$ ). ${ }^{44}$

\section{Postoperative renal failure}

As described in the previous section, multiple studies have found a relationship between the preoperative use of RAAS antagonists and the development of postoperative renal failure. ${ }^{78}$

The effect of the chronic RAAS inhibition on postoperative renal function was addressed by Arora et al in a retrospective cohort study (2001-2005) of 1358 patients who underwent cardiac surgery. The authors confirmed by multiple regression and propensity scores model a $27.6 \%$ higher risk of postoperative acute kidney injury (AKI) associated with preoperative use of ACEIs/ARBs. ${ }^{45}$

In a retrospective study (2000-2002) of 1209 adult patients undergoing coronary artery bypass graft, valve or combined procedures, Kincaid et al found an incidence of perioperative acute renal failure of $3.5 \%$, with a $48 \%$ incidence of mortality for the patients that developed renal failure. The most significant risk factor for development of acute renal failure was the preoperative use of ACEIs along with the intraoperative use of aprotinin (OR 2.9, 95\% CI 1.4 to 5.8; $\mathrm{p}<0.0001$ ). Interestingly, the effect of either drug alone was not significant. The proposed mechanism of this relationship is attributed to an aprotininmediated vasoconstriction of the afferent arteriole with subsequent reduction of the glomerular perfusion pressure in the setting of an ACEI-promoted vasodilatation of the efferent arteriole. $^{46}$

\section{Neuraxial anaesthesia}

The studies described in the previous section occurred in the setting of general anaesthesia with standard pharmacological protocols. The haemodynamic effects of neuraxial anaesthesia are related to the spinal level of anaesthesia; for instance, in thoracic epidural anaesthesia, hypotension results from attenuation of efferent sympathetic drive. ${ }^{47}$

The evidence on the effects of RAAS blockade in neuraxial anaesthesia is limited and contradictory. It has been shown that, in patients with preoperative use of ACEIs, there are increased concentrations of vasopressin and norepinephrine in the early phases of spinal anaesthesia that appear to attenuate the hypotensive effect of RAAS blockade. ${ }^{48-50}$ However, multiple cases of significant hypotension and bradycardia following spinal anaesthesia in patients chronically treated with ACEIs have been reported. ${ }^{51-55}$

Until further randomised studies are carried out to further clarify the best practice, it appears safe to stop RAAS blockade before spinal anaesthesia.

\section{EVIDENCE SUPPORTING RAAS ANTAGONISTS IN THE PERIOPERATIVE SETTING}

Although the basis for withholding RAAS antagonists on the morning of surgery is to avoid the risk of initial hypotension after the induction of anaesthesia, before the study by Miceli et $a l^{8}$ there had been no significant adverse effects (eg, mortality) related to the use of these agents reported in the literature. It was considered that, in certain cases, the preoperative use versus discontinuation of these agents should be factored into the overall risk-benefit equation, as certain groups of patients may benefit from its continuation (eg, systolic dysfunction, uncontrolled hypertension).

As part of their Physicians' Information and Education Resource, the American College of Physicians supports the cautious continuation of RAAS antagonists on the morning of surgery, with the caveat that euvolaemia should be maintained. ${ }^{56}$

Some authors suggest the continuation of ACEIs in patients with congestive heart failure, as the benefit may outweigh the risks-especially since hypotensive episodes are usually responsive to volume expansion and vasoconstrictors. ${ }^{17} 57$

The most important described beneficial effects of the perioperative use of RAAS antagonists include neuroprotection, improved haemodynamic stability, decreased POAF, limited ischaemia-reperfusion injury and renal protection. 


\section{Neuroprotection}

Tohmo et al described the use of preoperative enalapril as part of balanced hypotensive anaesthesia for cerebrovascular surgery. ${ }^{58}$ This is a technique in which controlled hypotension is used to minimise intraoperative bleeding and the need for transfusional support. ${ }^{59}$ Enalapril was associated with a decrease in the hypertensive response to intubation, lowered the requirements for postoperative vasodilators, and provided for more stable BP control compared with placebo. ${ }^{58}$ The authors theorised that preoperative fasting may be a more significant contributor to perioperative hypotension, and that the hypotension after induction of anaesthesia might be prevented by ensuring proper intravascular volume rather than withholding ACEIs before surgery. ${ }^{60}$

\section{Haemodynamic stability}

Sear et al measured the haemodynamic response to anaesthesia induction followed by laryngoscopy and intubation in 103 patients; 83 were already receiving one of four antihypertensive agents: ACEIs, BBs, CCBs and diuretics. Twenty-three patients were naïve to treatment. BP, cardiac output and stroke volume were monitored during induction of anaesthesia, intubation and maintenance of anaesthesia. Induction of anaesthesia caused hypotension and a decrease in cardiac output in all groups. Heart rate decreased in patients taking ACEIs and diuretics $(p<0.01)$, and systemic vascular resistance decreased in patients taking ACEIs and $\beta$ blockers $(p<0.05)$. BP and heart rate increased in all groups after laryngoscopy and intubation $(p<0.01)$, as did the systemic vascular resistance in patients taking ACEIs, BBs and diuretics $(p<0.02)$. In the group of untreated patients, the changes were similar. Comparison over time of all haemodynamic variables showed no differences between all groups. ${ }^{61}$

Pigott et al studied 40 patients undergoing CABG on chronic ACEI therapy; 20 patients continued ACEIs and 20 had ACEIs suspended before surgery. There was no significant difference between the groups in the frequency of hypotension during anaesthesia; however, the group in which ACEIs was withheld had postoperative hypertension that required the use of vasodilators. ${ }^{62}$

Some authors advocate preoperative ACEIs for all CAGB patients. Although intraoperative hypotension may develop, there is a concomitant postoperative increase in cardiac output and index. ${ }^{63}$

\section{Decreased POAF}

Ozaydin et al studied the effect of preoperative administration of ACEIs or ARBs on the development of POAF in patients undergoing cardiac surgery. The study involved 128 consecutive patients (ACEIs $(n=49)$, ACEIs plus candesartan $(n=49)$, control $(\mathrm{n}=30))$. The rate of POAF was higher in the control group (33.3\%) than the ACEI (12.2\% (RR 0.34, 95\% CI 0.12 to 0.93 ; $\mathrm{p}=0.03)$ ) or ACEI plus candesartan $(10.2 \%$ (RR $0.28,95 \% \mathrm{CI}$ 0.09 to $0.83 ; \mathrm{p}=0.02)$ ) group. $^{64}$

White et al evaluated the impact of preoperative ACEI or ARB use in the development of POAF after cardiac surgery (CABG or valvular surgery) in a cohort of 338 patients $(51.8 \% ; \mathrm{N}=175$ received preoperative $\mathrm{ACEIs}$ or $\mathrm{ARBs}$ ). The authors did not find an association between preoperative use of ACEIs/ARBs and reduction in POAF (adjusted OR 0.71, 95\% CI 0.42 to 1.20). They proposed that a larger number of patients would be needed to further evaluate the impact of preoperative ACEI or ARB use and POAF. ${ }^{65}$

A recent meta-analysis of 23 randomised control trials with 87048 patients showed that RAAS antagonists decreased the
OR for AF by $33 \%(p<0.00001)$, especially among patients with heart failure and those with hypertension and left ventricular hypertrophy. However, this meta-analysis was not designed in the perioperative context. ${ }^{66}$

The anti-arrhythmogenic potential of RAAS antagonists may be due to a sympatholytic effect or the attenuation of electrical and/or structural remodelling. RAAS antagonists also have antihypertensive properties with subsequent decrease in atrial and left ventricular end diastolic pressure. In addition, RAAS antagonists help prevent hypokalaemia. ${ }^{67}$

\section{Protection against ischaemia-reperfusion injury}

Boldt et al randomised 88 patients undergoing CABG into four groups of 22 patients each, to receive intravenous enalapril, enoximone (a phosphodiesterase inhibitor), clonidine or placebo (normal saline). The patients who received enalapril after induction of anaesthesia and before CPB had lower levels of cardiac enzyme release, suggesting that RAAS antagonists may have a cardioprotective effect against ischaemia-reperfusion injury. ${ }^{68}$ A similar finding was obtained by Benedetto et al in patients undergoing CABG with CPB. They compared 245 patients who received preoperative ACEIs with 236 patients who did not; the patients receiving preoperative ACE inhibitors had lower postoperative troponin I concentrations $(1.6 \mathrm{ng} / \mathrm{ml}$ (95\% CI 1.05 to 3.4 ) vs $2.4 \mathrm{ng} / \mathrm{ml}(95 \%$ CI 1.13 to 6.10$)$; $\mathrm{p}=0.0006)$. Although not significant, there was also a decreased rate of postoperative myocardial infarction $(2.0 \%$ vs $4.2 \%$; $\mathrm{p}=0.25)$ in patients receiving perioperative ACEIs. ${ }^{69}$

Licker et al allocated 20 patients into two groups: 11 patients received intravenous enalapril $50 \mu \mathrm{g} / \mathrm{kg}$ and nine patients received normal saline at the time of anaesthesia induction for aortic surgery. After infrarenal aortic cross-clamping, the investigators found that the preoperative administration of enalapril was associated with enhanced systemic oxygen delivery, improved splanchnic perfusion and improved GFR $24 \mathrm{~h}$ after surgery. ${ }^{70}$

\section{Renal protection}

Temporary withdrawal of RAAS antagonists may be expected to increase RAAS activity. The potential loss of BP control may be at the expense of impaired regional circulation as demonstrated by several studies that show the preservation and even improvement of renal function in patients receiving ACEIs before surgery. ${ }^{17}$

In a randomised double-blind study, Colson et al compared short-term (2 days) preoperative treatment with captopril with placebo in 18 patients undergoing CABG. Captopril-treated patients had improved renal plasma flow and GFR during bypass compared with placebo-treated patients. ${ }^{71}$

In a study of 536 patients by Benedetto et al, the effect of preoperative ACEIs on AKI (defined as a postoperative decrease in GFR of $>50 \%$ from the preoperative value) was evaluated after $\mathrm{CABG}$ with $\mathrm{CPB}$. Of the 536 patients, 281 received ACEI inhibitors before surgery. The incidence of AKI was $6.4 \%$ in the ACEI group and $12.2 \%$ in the control group $(p=0.02)$. The incidence of AKI requiring dialysis was $2.4 \%$ in the ACEI group and $6.3 \%$ in the controls $(\mathrm{p}=0.03$ ). The authors found that preoperative ACEIs was associated with a decreased incidence of postoperative AKI (OR 0.48 , 95\% CI 0.23 to 0.77 ; $\mathrm{p} \leq 0.04$ ) after on-pump CABG surgery. ${ }^{72}$

\section{Adverse consequences of RAAS antagonist cessation}

The benefit of ACEIs in patients with systolic heart failure is well documented. Groban and Butterworth recommend that 
ACEIs should be continued before surgery in patients with heart failure in both cardiac and non-cardiac surgery, as the benefits outweigh the potential risks. Careful expansion of intravascular volume should occur before induction of anaesthesia, and any brief episodes of hypotension should be treated with sympathomimetics. ${ }^{17}$ In the case of refractory hypotension either during non-cardiac surgery or on weaning from CPB during cardiac surgery, vasopressin or vasopressin antagonists can be used. ${ }^{18} 73$ Careful selection of anaesthetic agents less likely to cause hypotension (eg, etomidate) as well as sequential administration of the anaesthetic agents may prevent or attenuate the hypotensive response to anaesthesia. ${ }^{17}$ An important consideration in the heart failure patient is the concurrent use of multiple drugs, including antiarrhythmics such as amiodarone. Mackay et al reported two cases of refractory hypotension in anaesthetised patients under CPB who received amiodarone in combination with ACE. ${ }^{74}$

There is very limited evidence about the perioperative consequences of withdrawing RAAS antagonists in the setting of heart failure with preserved EF (diastolic heart failure). Careful haemodynamic monitoring of these patients, including strict $\mathrm{BP}$ control, is recommended. It is important to avoid hypertensive crises which may precipitate the development of flash pulmonary oedema. ${ }^{75-77}$

\section{OTHER RAAS ANTAGONISTS - THE DIRECT RENIN INHIBITORS}

Because renin controls the rate-limiting step in the RAAS cascade, the blockage of its receptors is an optimal target for RAAS suppression. Aliskiren is the first direct renin inhibitor approved by the Food and Drug Administration for treating hypertension. It has a long half-life $(30-40 \mathrm{~h})$, as well as an increased renal vasodilatory effect compared with ACEIs and ARBs. However, owing to its low oral bioavailability (up to $90 \%$ excreted unchanged in faeces), its terminal half-life is $24 \mathrm{~h}$. It is a second-line agent and generally considered a weak antihypertensive. It should preferably be used in combination with natriuretic agents or ARBs. ${ }^{78-82}$ No long-term outcome data on its use are available at this time. Consequently, there are no data to guide its use in the perioperative setting. However, we hypothesise that, given its pharmacological properties, the last dose should be given at least $24 \mathrm{~h}$ before scheduled surgery, and clinical trials should be pursued to address its effect on perioperative BP control and outcomes.

\section{OTHER RAAS ANTAGONISTS - THE ALDOSTERONE ANTAGONISTS}

The final pathway in RAAS is the stimulation of aldosterone production and release from the zona glomerulosa of the adrenal cortex. This hormone is a mineralocorticoid that increases the renal absorption of water and sodium and enhances renal potassium excretion. Its final effect is an increase in circulating blood volume. Elevated concentrations of aldosterone are associated with increased mortality in heart failure. In patients with cirrhosis and portal hypertension, elevated concentrations of aldosterone are associated with the development of ascites. The pathophysiological mechanisms of aldosterone in heart failure and portal hypertension are beyond the scope of this review. However, given its deleterious effect in heart failure, aldosterone blockade has emerged as a mainstay of treatment in advanced heart failure (New York Heart Association class III and IV). Also, because of its hyperkaliuric properties, the use of aldosterone blockers are commonly used as 'potassium-sparing' diuretics.

\section{Main messages}

The renin-angiotensin-aldosterone system (RAAS) antagonists include: ACE inhibitors (ACEls), angiotensin 1 receptor blockers (ARBs) and aliskiren (direct renin inhibitor), as well as the aldosterone antagonists (spironolactone, eplerenone).

- The preoperative use of RAAS antagonists is associated with significant hypotensive episodes after induction of anaesthesia requiring the use of systemic vasopressor drugs.

- Recently, increased morbidity and mortality have been shown in patients undergoing coronary artery bypass grafting who continue ACE inhibitors before surgery.

- In patients who are using RAAS antagonists and will undergo surgery, RAAS should be withheld one half-life before induction of anaesthesia.

- If it is not possible to withhold RAAS antagonists before induction of anaesthesia (eg, emergency surgery), the anaesthesiologist should maintain adequate intravenous volume and perform careful haemodynamic monitoring.

There are two known aldosterone antagonists-spironolactone and eplerenone. The first one is well known as a diuretic agent, ${ }^{83}$ and the second is used in patients who develop heart failure after myocardial infarction, but may also be used in patients with heart failure of any aetiology who are intolerant of spironolactone. The evidence supporting the use or discontinuation of spironolactone or eplerenone in the perioperative setting is scant except for the recommendation of continuation of these agents in patients undergoing resection of aldosterone-producing tumours.

Given their mineralocorticoid antagonist activity, as well as the diuretic effect of spironolactone, we recommend withholding these agents before surgery to minimise intraoperative hypotension as well as electrolyte derangement, especially hyperkalaemia.

\section{CONCLUSIONS AND RECOMMENDATIONS}

The use of RAAS antagonists (ACEIs/ARBs) has been associated with a variable incidence of intraoperative hypotension after induction of anaesthesia; at the present time, there is growing evidence linking the preoperative use of these agents with postoperative adverse effects including worsening of renal function and even death.

In certain cases (eg, uncontrolled hypertension, systolic dysfunction), continuation of RAAS antagonists may be

\section{Current research questions}

- A large prospective randomised controlled trial comparing the preoperative administration versus withdrawal of ACE inhibitors, angiotensin II receptor subtype 1 blockers and placebo is required to further clarify the safety of the preoperative use of these agents.

- Further studies should include the direct renin inhibitor aliskiren.

- New insights in pharmacogenomics suggest the study of the preoperative use versus discontinuation of RAAS antagonists in different populations. 


\section{Key references}

Fyhrquist F, Saijonmaa 0. Renin-angiotensin system revisited. J Intern Med 2008;264:224-36.

- Colson P, Ryckwaert F, Coriat P. Renin angiotensin system antagonists and anesthesia. Anesth Analg 1999;89:1143-55.

- Comfere T, Sprung J, Kumar MM, et al. Angiotensin system inhibitors in a general surgical population. Anesth Analg 2005;100:636-44, table of contents.

- Saber W. Peri-operative medication management: a casebased review of general principles. Cleve Clin J Med 2006;73 (Suppl 1):S82-7.

- Schirmer U, Schurmann W. Preoperative administration of angiotensin-converting enzyme inhibitors. Anaesthesist 2007;56:557-61.

- Rosenman DJ, McDonald FS, Ebbert JO, et al. Clinical consequences of withholding versus administering reninangiotensin-aldosterone system antagonists in the preoperative period. J Hosp Med 2008;3:319-25.

- Raja SG, Fida N. Should angiotensin converting enzyme inhibitors/angiotensin II receptor antagonists be omitted before cardiac surgery to avoid postoperative vasodilation? Interact Cardiovasc Thorac Surg 2008;7(3):470-5.

- Miceli A, Capoun R, Fino C, et al. Effects of ACE inhibitor therapy on clinical outcome in patients undergoing coronary artery bypass grafting. J Am Coll Cardiol 2009;54:1778-84.

considered after a full discussion with the anaesthesiologist and surgeon, along with maintenance of careful intraoperative haemodynamic monitoring and adequate intravenous volume status before induction of anaesthesia.

Temporary withdrawal of RAAS antagonists may prevent or attenuate intraoperative hypotension and hypovolaemia. The current practice in our institution is to avoid the use of ACEIs and $A R B s$ on the morning of surgery.

\section{MULTIPLE-CHOICE QUESTIONS (TRUE (T)/FALSE (F); ANSWERS BEFORE THE REFERENCES)}

1. The drug aliskiren is a direct renin inhibitor.

2. The vasodilatory actions of RAAS antagonists involve:

A. sympathetic blockade

B. decreased bioavailability of bradykinin, nitric oxide and prostacyclins

C. inhibition of the direct and indirect vasoconstrictor effects of angiotensin II

D. increased secretion of aldosterone

E. increased secretion of antidiuretic hormone

3. The preoperative administration of captopril $25 \mathrm{mg}$ increases the likelihood of hypotension following induction of anaesthesia compared with a dose of $12.5 \mathrm{mg}$

4. The preoperative use of ARBs is associated with an increased frequency of refractory intraoperative hypotension compared with ACEIs

5. The use of RAAS antagonists in non-cardiac surgery:

A. is not associated with an increased need for postinduction vasopressor agents

B. may require the use of vasopressin and its analogues to respond to hypotension that is refractory to adrenergic agents
C. is associated with increased risk of death

D. is not associated with postoperative renal failure

Competing interests None.

Provenance and peer review Not commissioned; externally peer reviewed.

\section{ANSWERS}

1. (T)

The RAAS antagonists include ACE inhibitors, angiotensin II receptor subtype 1 blockers and direct renin inhibitors (eg, aliskiren).

2. $A(T) ; B(F) ; C(T) ; D(F)$; $(F)$

The vasodilatory actions of RAAS antagonists involve multiple mechanisms, which include direct sympathetic blockade, increased bioavailability of vasodilators such as bradykinin, nitric oxide and prostacyclins, inhibition of the direct and indirect vasoconstrictor effects of angiotensin II, and reduced secretion of aldosterone and antidiuretic hormone leading to a decrease in salt and water reabsorption by the kidney. Given the wide distribution of ACE in the body, the RAAS antagonists have wide-ranging effects, secondary to the inhibition of various angiotensin peptides as well as both renin and pro-renin receptors with endocrine, paracrine and intracrine functions, which in turn regulate diverse physiological functions

3. (F)

McCarthy et al studied the effect of two doses of sublingual captopril $112.5 \mathrm{mg}$ and $25 \mathrm{mg}$ ) versus placebo administered 25 min before tracheal intubation in 40 patients. The patients receiving captopril had increased hypotension compared with those receiving placebo $(p<0.05)$ within 3 min of intubation; however, there was no significant difference between the two captopril doses.

4. (T)

The different haemodynamic response between ACEls and ARBs was demonstrated by Brabant comparing the responses between patients treated with beta-adrenergic blockers (BBs) and/or calcium channel blockers (CBs), ACEls or ARBs after induction of anaesthesia. The administration of ARBs was associated with more common and more severe hypotensive episodes compared with ACEls, BBs and CBs.

5. A $(F) ; B(T) ; C(F)$; D (T)

The most common adverse effect of the preoperative administration (within $10 \mathrm{~h}$ of surgery) of RAAS antagonists is a significant fall in BP after induction of anaesthesia. This hypotension may not respond to volume resuscitation alone and may require the use of vasopressor agents. The hypotensive episodes seen with RAAS antagonists are often refractory to adrenergic agents and vasopressin analogues should be used. To date, the observed increase in hypotension has not been directly linked to major cardiovascular complications (myocardial ischaemia, heart failure), stroke, renal failure, length of stay in the intensive care unit or increased mortality.

\section{REFERENCES}

1. Matchar DB, McCrory DC, Orlando LA, et al. Systematic review: comparative effectiveness of angiotensin-converting enzyme inhibitors and angiotensin II receptor blockers for treating essential hypertension. Ann Intern Med 2008; 148:16-29.

2. Lakhdar R, Al-Mallah MH, Lanfear DE. Safety and tolerability of angiotensinconverting enzyme inhibitor versus the combination of angiotensin-converting enzyme inhibitor and angiotensin receptor blocker in patients with left ventricular dysfunction: a systematic review and meta-analysis of randomized controlled trials. J Card Fail 2008;14:181-8.

3. Winkelmayer WC, Fischer MA, Schneeweiss $S$, et al. Angiotensin inhibition after myocardial infarction: does drug class matter? J Gen Intern Med 2006;21:1242-7.

4. Casas JP, Chua W, Loukogeorgakis S, et al. Effect of inhibitors of the reninangiotensin system and other antihypertensive drugs on renal outcomes: systematic review and meta-analysis. Lancet 2005;366:2026-33.

5. Stojiljkovic L, Behnia R. Role of renin angiotensin system inhibitors in cardiovascular and renal protection: a lesson from clinical trials. Curr Pharm Des 2007; 13:1335-45.

6. Colson $\mathbf{P}$, Ryckwaert F, Coriat $P$. Renin angiotensin system antagonists and anesthesia. Anesth Analg 1999;89:1143-55.

7. Cittanova ML, Zubicki A, Savu C, et al. The chronic inhibition of angiotensinconverting enzyme impairs postoperative renal function. Anesth Analg 2001;93:1111-15.

8. Miceli A, Capoun R, Fino C, et al. Effects of angiotensin-converting enzyme inhibitor therapy on clinical outcome in patients undergoing coronary artery bypass grafting. J Am Coll Cardiol 2009;54:1778-84. 
9. Brown NJ, Vaughan DE. Angiotensin-Converting Enzyme Inhibitors. Circulation 1998;97:1411-20

10. Barreras A, Gurk-Turner C. Angiotensin II receptor blockers. Proc (Bayl Univ Med Cent) 2003;16:123-6.

11. Varin R, Mulder P, Tamion F, et al. Improvement of endothelial function by chronic angiotensin-converting enzyme inhibition in heart failure: role of nitric oxide prostanoids, oxidant stress, and bradykinin. Circulation 2000;102:351-6.

12. Fyhrquist F, Saijonmaa O. Renin-angiotensin system revisited. J Intern Med 2008;264:224-36.

13. Hanif K, Bid HK, Konwar R. Reinventing the ACE inhibitors: some old and new implications of ACE inhibition. Hypertens Res 2010;33:11-21.

14. Ferrario CM. New physiological concepts of the renin-angiotensin system from the investigation of precursors and products of angiotensin I metabolism. Hypertension 2010;55:445-52.

15. Varagic J, Trask AJ, Jessup JA, et al. New angiotensins. J Mol Med 2008;86:663-71.

16. Behnia R, Molteni A, Igic R. Angiotensin-converting enzyme inhibitors: mechanisms of action and implications in anesthesia practice. Curr Pharm Des 2003;9:763-76

17. Groban L, Butterworth J. Perioperative management of chronic heart failure. Anesth Analg 2006;103:557-75.

18. Jochberger S, Wenzel V, Dunser MW. Arginine vasopressin as a rescue vasopressor agent in the operating room. Curr Opin Anaesthesiol 2005; 18:396-404.

19. Coriat P. Renin angiotensin aldosterone systems blockade and perioperative left ventricular function. Semin Cardiothorac Vasc Anesth 2003:7:55-8.

20. Su X, Lee L, Li X, et al. Association between angiotensinogen, angiotensin II receptor genes, and blood pressure response to an angiotensin-converting enzyme inhibitor. Circulation 2007;115:725-32

21. Jeunemaitre $\mathbf{X}$. Genetics of the human renin angiotensin system. J Mol Med 2008:86:637-41.

22. Brugts JJ, den Uil CA, Danser $\mathrm{AH}$, et al. The renin-angiotensin-aldosterone system: approaches to guide angiotensin-converting enzyme inhibition in patients with coronary artery disease. Cardiology 2009:112:303-12.

23. Rudnicki M, Mayer G. Significance of genetic polymorphisms of the renin-angiotensin-aldosterone system in cardiovascular and renal disease. Pharmacogenomics 2009;10:463-76.

24. Saber W. Perioperative medication management: a case-based review of genera principles. Cleve Clin J Med 2006;73 (Suppl1):S82-7.

25. McCarthy GJ, Hainsworth M, Lindsay K, et al. Pressor responses to tracheal intubation after sublingual captopril. A pilot study. Anaesthesia 1990:45:243-5.

26. Coriat $\mathbf{P}$, Richer $\mathrm{C}$, Douraki $\mathrm{T}$, et al. Influence of chronic angiotensin-converting enzyme inhibition on anesthetic induction. Anesthesiology 1994;81:299-307.

27. Brabant SM, Bertrand M, Eyraud D, et al. The hemodynamic effects of anesthetic induction in vascular surgical patients chronically treated with angiotensin II receptor antagonists. Anesth Analg 1999:89:1388-92.

28. Bertrand M, Godet G, Meersschaert K, et al. Should the angiotensin II antagonists be discontinued before surgery? Anesth Analg 2001;92:26-30.

29. Comfere T, Sprung J, Kumar MM, et al. Angiotensin system inhibitors in a general surgical population. Anesth Analg 2005;100:636-44.

30. Schirmer U, Schurmann W. Preoperative administration of angiotensin-converting enzyme inhibitors. Anaesthesist 2007:56:557-61.

31. Licker M, Schweizer A, Hohn L, et al. Cardiovascular responses to anesthetic induction in patients chronically treated with angiotensin-converting enzyme inhibitors. Can J Anaesth 2000:47:433-40.

32. Rosenman DJ, McDonald FS, Ebbert JO, et al. Clinical consequences of withholding versus administering renin-angiotensin-aldosterone system antagonists in the preoperative period. J Hosp Med 2008;3:319-25.

33. Kheterpal S, Khodaparast 0, Shanks A, et al. Chronic angiotensin-converting enzyme inhibitor or angiotensin receptor blocker therapy combined with diuretic therapy is associated with increased episodes of hypotension in noncardiac surgery. $J$ Cardiothorac Vasc Anesth 2008;22:180-6.

34. Railton CJ, Wolpin J, Lam-McCulloch J, et al. Renin-angiotensin blockade is associated with increased mortality after vascular surgery. Can J Anaesth 2010;57:736-44.

35. Colson $\mathbf{P}$, Saussine M, Seguin JR, et al. Hemodynamic effects of anesthesia in patients chronically treated with angiotensin-converting enzyme inhibitors. Anesth Analg 1992:74:805-8.

36. Tuman KJ, McCarthy RJ, O'Connor CJ, et al. Angiotensin-converting enzyme inhibitors increase vasoconstrictor requirements after cardiopulmonary bypass. Anesth Analg 1995:80:473-9.

37. Deakin CD, Dalrymple-Hay MJ, Jones $P$, et al. Effects of angiotensin converting enzyme inhibition on systemic vascular resistance and vasoconstrictor requirements during hypothermic cardiopulmonary bypass. Eur J Cardiothorac Surg 1998; 13:546-50.

38. Levin MA, Lin HM, Castillo JG, et al. Early on-cardiopulmonary bypass hypotension and other factors associated with vasoplegic syndrome. Circulation 2009;120:1664-71.

39. Magee MJ, Herbert MA, Dewey TM, et al. Atrial fibrillation after coronary artery bypass grafting surgery: development of a predictive risk algorithm. Ann Thorac Surg 2007;83:1707-12
40. Argenziano M, Chen JM, Choudhri AF, et al. Management of vasodilatory shock after cardiac surgery: identification of predisposing factors and use of a novel pressor agent. J Thorac Cardiovasc Surg 1998;116:973-80.

41. Lee YK, Na SW, Kwak YL, et al. Effect of pre-operative angiotensin-converting enzyme inhibitors on haemodynamic parameters and vasoconstrictor requirements in patients undergoing off-pump coronary artery bypass surgery. J Int Med Res 2005;33:693-702.

42. Boeken U, Feindt $P$, Mohan $E$, et al. Post-perfusion syndrome and disturbed microcirculation after cardiac surgery: the role of angiotensin-converting-enzyme inhibitors. Thorac Cardiovasc Surg 1999;47:347-51.

43. Raja SG, Fida N. Should angiotensin converting enzyme inhibitors/angiotensin II receptor antagonists be omitted before cardiac surgery to avoid postoperative vasodilation? Interact Cardiovasc Thorac Surg 2008;7:470-5.

44. Rader F, Van Wagoner DR, Gillinov AM, et al. Preoperative angiotensin-blocking drug therapy is not associated with atrial fibrillation after cardiac surgery. Am Heart $J$ 2010; 160:329-36.

45. Arora P, Rajagopalam S, Ranjan R, et al. Preoperative use of angiotensin-converting enzyme inhibitors/angiotensin receptor blockers is associated with increased risk for acute kidney injury after cardiovascular surgery. Clin J Am Soc Nephrol 2008;3:1266-73.

46. Kincaid EH, Ashburn DA, Hoyle JR, et al. Does the combination of aprotinin and angiotensin-converting enzyme inhibitor cause renal failure after cardiac surgery? Ann Thorac Surg 2005:80:1388-93.

47. Scavone BM, Ratliff J, Wong CA. Physiologic effects of neuraxial anesthesia In: Wong CA, ed. Spinal and Epidural Anesthesia. Mc Graw Hill, 2007:Chap 4:111-27.

48. Hohne C, Meier L, Boemke W, et al. ACE inhibition does not exaggerate the blood pressure decrease in the early phase of spinal anaesthesia. Acta Anaesthesiol Scand 2003;47:891-6.

49. Hopf HB, Arand D, Peters J. Sympathetic blockade by thoracic epidural anaesthesia suppresses renin release in response to hypotension, but activates the vasopressin system. Eur J Anaesthesiol 1992;9:63-9.

50. Hopf HB, Schlaghecke R, Peters J. Sympathetic neural blockade by thoracic epidura anesthesia suppresses renin release in response to arterial hypotension. Anesthesiology 1994;80:992-9; discussion 27A-28A.

51. Castanon E, Gutierrez C, Fernandez FE, et al. Influence of angiotensin-converting enzyme inhibitors during spinal anesthesia. Rev Esp Anestesiol Reanim 1995; $\mathbf{4 2 : 3 6 - 7}$

52. Cozanitis DA. The importance of interrupting angiotensin converting enzyme inhibitor treatment before spinal anaesthesia-a controlled case report. Anaesthesio Reanim 2004;29:16-18

53. Pose Reino A, Pena Seijo M, Baltar Martinez de la Riva A. Severe hypotension during spinal anesthesia induced by angiotensin-converting enzyme inhibitors (In Spanish). Med Clin (Barc) 2008;130:159.

54. Williams NE. Profound bradycardia and hypotension following spinal anaesthesia in a patient receiving an ACE inhibitor: an important 'drug' interaction? Eur $J$ Anaesthesiol 1999:16:796-8.

55. Akinci SB, Ayhan B, Kanbak M, et al. Refractory hypotension in a patient chronically treated with a long acting angiotensin-converting enzyme inhibitor. Anaesth Intensive Care 2004;32:722-3.

56. Cohn SL. Perioperative cardiovascular medication management. In: ACP PIER Perioperative Medication Management. 2010. http://pier.acponline.org/physicians/ diseases/d835/pdf/d835.pdf.

57. Smith I, Jackson I. Beta-blockers, calcium channel blockers, angiotensin converting enzyme inhibitors and angiotensin receptor blockers: should they be stopped or not before ambulatory anaesthesia? Curr Opin Anaesthesiol 2010;23:687-90

58. Tohmo H, Karanko M, Scheinin M, et al. Enalapril premedication attenuates the blood pressure response to tracheal intubation and stabilizes postoperative blood pressure after controlled hypotension with sodium nitroprusside in neurovascular patients. J Neurosurg Anesthesiol 1993:5:13-21.

59. Degoute CS. Controlled hypotension: a guide to drug choice. Drugs 2007:67:1053-76.

60. Tohmo H, Karanko M. Angiotensin-converting enzyme inhibitors and anaesthesia. Acta Anaesthesiol Scand 1996;40:132-3.

61. Sear JW, Jewkes C, Tellez JC, et al. Does the choice of antihypertensive therapy influence haemodynamic responses to induction, laryngoscopy and intubation?. Br J Anaesth 1994;73:303-8

62. Pigott DW, Nagle C, Allman K, et al. Effect of omitting regular ACE inhibitor medication before cardiac surgery on haemodynamic variables and vasoactive drug requirements. Br J Anaesth 1999;83:715-20.

63. Lazar HL. The use of angiotensin-converting enzyme inhibitors in patients undergoing coronary artery bypass graft surgery. Vascul Pharmacol 2005;42:119-23.

64. Ozaydin M, Dede 0 , Varol $\mathrm{E}$, et al. Effect of renin-angiotensin aldosterone system blockers on postoperative atrial fibrillation. Int J Cardiol 2008:127:362-7.

65. White CM, Kluger J, Lertsburapa K, et al. Effect of preoperative angiotensin converting enzyme inhibitor or angiotensin receptor blocker use on the frequency of atrial fibrillation after cardiac surgery: a cohort study from the atrial fibrillation suppression trials II and III. Eur J Cardiothorac Surg 2007:31:817-20.

66. Schneider MP, Hua TA, Böhm M, et al. Prevention of atrial fibrillation by renin-angiotensin system inhibition. J Am Coll Cardiol 2010;55:2299-307. 
67. Ozaydin M, Varol E, Türker Y, et al. Association between renin-angiotensinaldosterone system blockers and postoperative atrial fibrillation in patients with mild and moderate left ventricular dysfunction. Anadolu Kardiyol Derg 2010;10:137-42.

68. Boldt J, Rothe G, Schindler E, et al. Can clonidine, enoximone, and enalaprilat help to protect the myocardium against ischaemia in cardiac surgery? Heart 1996:76:207-13.

69. Benedetto U, Melina G, Capuano F, et al. Preoperative angiotensin-converting enzyme inhibitors protect myocardium from ischemia during coronary artery bypass graft surgery. J Cardiovasc Med (Hagerstown) 2008;9:1098-103.

70. Licker M, Bednarkiewicz M, Neidhart P, et al. Preoperative inhibition of angiotensin-converting enzyme improves systemic and renal haemodynamic changes during aortic abdominal surgery. Br J Anaesth 1996;76:632-9.

71. Colson P, Ribstein J, Mimran A, et al. Effect of angiotensin converting enzyme inhibition on blood pressure and renal function during open heart surgery. Anesthesiology 1990;72:23-7.

72. Benedetto U, Sciarretta S, Roscitano A, et al. Preoperative angiotensin-converting enzyme inhibitors and acute kidney injury after coronary artery bypass grafting. Ann Thorac Surg 2008;86:1160-5.

73. Boccara G, Ouattara A, Godet G, et al. Terlipressin versus norepinephrine to correct refractory arterial hypotension after general anesthesia in patients chronically treated with renin-angiotensin system inhibitors. Anesthesiology 2003:98:1338-44
74. Mackay JH, Walker IA, Bethune DW. Amiodarone and anaesthesia: Concurrent therapy with ACE inhibitors-an additional cause for concern? Can J Anaesth 1991;38:687.

75. Pirracchio R, Cholley B, De Hert S, et al. Diastolic heart failure in anaesthesia and critical care. Br J Anaesth 2007:98:707-21.

76. Sanders D, Dudley M, Groban L. Diastolic dysfunction, cardiovascular aging, and the anesthesiologist. Anesthesiol Clin 2009;27:497-517.

77. Alsaddique AA, Royse AG, Royse CF. Management of diastolic heart failure following cardiac surgery. Eur J Cardiothorac Surg 2009:35:241-9.

78. Fischer $\mathbf{N}$, Hollenberg N. Unprecedented renal responses to direct blockade of the renin-angiotensin-system with aliskiren, a novel renin inhibitor. Abstract 2520. Circulation 2007:116: II 556.

79. Gradman $\mathbf{A H}, \mathrm{Kad}$ R. Renin inhibition in hypertension. J Am Coll Cardiol 2008;51:519-28.

80. Brown MJ. Aliskiren. Circulation 2008;118:773-84

81. Daugherty KK. Aliskiren. Am J Health Syst Pharm 2008;65:1323-32.

82. Abassi Z, Winaver J, Feuerstein GZ. The biochemical pharmacology of renin inhibitors: implications for translational medicine in hypertension, diabetic nephropathy and heart failure: expectations and reality. Biochem Pharmacol 2009; 78:933-40.

83. Marrs JC. Spironolactone management of resistant hypertension. Ann Pharmacother 2010;44:1762-9. 